\title{
Effect of a glucose impulse on the CcpA regulon in Staphylococcus
}

\section{aureus}

\author{
Kati Seidl ${ }^{1}$, Susanne Müller ${ }^{1}$, Patrice François ${ }^{2}$, Carsten Kriebitzsch ${ }^{3}$, \\ Jacques Schrenzel ${ }^{2}$, Susanne Engelmann ${ }^{3}$, Markus Bischoff ${ }^{1,4}$ and \\ Brigitte Berger-Bächi*1
}

Address: ${ }^{1}$ Institute of Medical Microbiology, University of Zürich, Zürich, Switzerland, ${ }^{2}$ Service of Infectious Diseases/Genomic Research Laboratory, University of Geneva Hospitals, Geneva, Switzerland, 3institute of Microbiology, University of Greifswald, Greifswald, Germany and ${ }^{4}$ Institute of Medical Microbiology and Hygiene, University of Saarland Hospital, Homburg/Saar, Germany

Email: Kati Seidl - katiseidl@gmail.com; Susanne Müller - kurzaz@ggaweb.ch; Patrice François - patrice.francois@genomic.ch; Carsten Kriebitzsch - carsten.kriebitzsch@med.kuleuven.be; Jacques Schrenzel - jacques.schrenzel@hcuge.ch;

Susanne Engelmann - susanne.engelmann@uni-greifswald.de; Markus Bischoff - markus.bischoff@uniklinikum-saarland.de; Brigitte BergerBächi* - bberger@imm.uzh.ch

* Corresponding author

Published: 18 May 2009

BMC Microbiology 2009, 9:95 doi:10.1 186/147|-2180-9-95
Received: 4 September 2008

Accepted: 18 May 2009

This article is available from: http://www.biomedcentral.com/I47/-2/80/9/95

(c) 2009 Seidl et al; licensee BioMed Central Ltd.

This is an Open Access article distributed under the terms of the Creative Commons Attribution License (http://creativecommons.org/licenses/by/2.0), which permits unrestricted use, distribution, and reproduction in any medium, provided the original work is properly cited.

\begin{abstract}
Background: The catabolite control protein A (CcpA) is a member of the Lacl/GalR family of transcriptional regulators controlling carbon-metabolism pathways in low-GC Gram-positive bacteria. It functions as a catabolite repressor or activator, allowing the bacteria to utilize the preferred carbon source over secondary carbon sources. This study is the first CcpA-dependent transcriptome and proteome analysis in Staphylococcus aureus, focussing on short-time effects of glucose under stable $\mathrm{pH}$ conditions.

Results: The addition of glucose to exponentially growing $S$. aureus increased the expression of genes and enzymes of the glycolytic pathway, while genes and proteins of the tricarboxylic acid (TCA) cycle, required for the complete oxidation of glucose, were repressed via CcpA. Phosphotransacetylase and acetate kinase, converting acetyl-CoA to acetate with a concomitant substrate-level phosphorylation, were neither regulated by glucose nor by $\mathrm{C} c \mathrm{~A}$. С $\mathrm{cpA}$ directly repressed genes involved in utilization of amino acids as secondary carbon sources. Interestingly, the expression of a larger number of genes was found to be affected by ccpA inactivation in the absence of glucose than after glucose addition, suggesting that glucose-independent effects due to CcpA may have a particular impact in S. aureus. In the presence of glucose, CcpA was found to regulate the expression of genes involved in metabolism, but also that of genes coding for virulence determinants.
\end{abstract}

Conclusion: This study describes the CcpA regulon of exponentially growing S. aureus cells. As in other bacteria, $\mathrm{Ccp} A$ of $S$. aureus seems to control a large regulon that comprises metabolic genes as well as virulence determinants that are affected in their expression by CcpA in a glucosedependent as well as -independent manner. 


\section{Background}

Staphylococcus aureus is one of the leading causes for nosocomial infections. It has been the subject of intensive research for many years and there is a large amount of data available concerning the regulation, function, and structure of various virulence factors. Recent studies suggest that basic physiology determines not only growth and survival but also pathogenicity and adaptation to environmental conditions. Therefore, more knowledge about cell physiology and molecular processes involved in infection is necessary to better understand staphylococcal pathogenicity.

One of the important and highly conserved regulators of carbon catabolite regulation in low-GC Gram-positive bacteria is the catabolite control protein A, CcpA, which has been intensively studied in Bacillus subtilis [1,2]. In the presence of glucose or other rapidly metabolized carbon sources, CcpA is activated by complex formation with the corepressor Hpr that has been phosphorylated on residue Ser46. Hpr has dual functions; it can be phosphorylated either at Ser46 or at His15. In the latter form, it acts in the sugar phosphotransferase system (PTS) for sugar uptake. The CcpA(Hpr-Ser46P) complex has an increased affinity for particular cis-acting sequences, termed cre-sites (catabolite responsive elements), and thereby represses or enhances gene expression, depending on the position of the cre in relation to the operator sequence $[3,4]$. These cis-acting DNA sequences have been extensively studied through mutagenesis [3-8], however, the consensus sequences differ slightly from study to study. In $B$. subtilis, a second corepressor, Crh, which is highly homologous to Hpr, but can only be phosphorylated at Ser46, can also form a complex and thus activate CcpA [9]. While $S$. aureus possesses a HPr-homologue, no Crh-homologue can be found in this organism [10].

CcpA has been shown to play a similar role in controlling metabolism in other bacteria, such as Bacillus cereus [11], Staphylococcus xylosus [12], Lactococcus lactis [13], Streptococcus pneumoniae [14], Streptococcus mutans [15], and Listeria monocytogenes [16]. In addition to its role in metabolism, CcpA was reported to regulate the expression of several virulence factors and to be involved in antibiotic resistance $[14,15,17-24]$.

The aim of this study was to gain a genome wide overview of the genes and proteins subject to CcpA-control in $S$. aureus during exponential growth in a $\mathrm{pH}$-controlled environment, in the absence of additional glucose and $30 \mathrm{~min}$ after glucose addition.

\section{Results and discussion Physiological characteristics of the Newman wild-type and its $\triangle$ ccpA mutant}

The transcriptomes of strain Newman and its isogenic $\triangle c c p A$ mutant MST14 were analyzed in LB, a complex medium essentially free of glucose and other rapidly catabolizable sugars [25], under controlled pH conditions in exponential growth $\left(\mathrm{OD}_{600}\right.$ of 1$)$, and $30 \mathrm{~min}$ after the addition of $10 \mathrm{mM}$ glucose. In the absence of glucose, the wild-type had a slightly lower doubling time than the mutant $(25.7 \pm 1.29$ min versus $31.8 \pm 1.29 \mathrm{~min}, P<$ $0.01)$. The addition of $10 \mathrm{mM}$ glucose at $\mathrm{OD}_{600}$ of 1 increased the growth rate of the wild-type but had only a minor effect on that of the mutant (Fig. 1). 60 min after glucose addition, glucose was depleted from the medium down to $0.3 \mathrm{mM}$ by the wild-type, while still $3 \mathrm{mM}$ of glucose were left in the culture of the mutant (Fig. 1). Despite increased growth and glucose consumption rates in the wild-type culture, acetate production was only slightly enhanced compared to the mutant, in line with previous findings [24]. No lactate was excreted under these conditions at any time point sampled, confirming the aerobic growth conditions. Acidification of the medium upon glucose metabolism was prevented by HEPES-buffering, which allowed maintaining the $\mathrm{pH}$ of the growth media at 7.5 for both strains and under both growth conditions for at least $2 \mathrm{~h}$ past glucose addition.

\section{Transcriptome analysis}

The total number of genes, which were expressed at a sufficient level to give meaningful data, was 2479. 111 of these genes had no homologues in strain Newman, and were therefore excluded from the analysis. Of the 2368 remaining genes, a total of 155 were found to be affected upon glucose addition in a CcpA-dependent manner, while 21 genes seemed to be controlled by CcpA and other regulatory proteins at the same time in the presence of glucose, and 10 genes exhibited CcpA-independent glucose effects. The largest group, comprising 226 genes, however, was affected by $c c p A$ inactivation even without glucose addition to the LB medium (Table 1). While regulatory classes partly overlapped, the overall range of differential gene expression was only narrow, peaking around 2- to 3-fold induction or repression.

In order to support our microarray findings, we analyzed the expression of five genes showing differential expression in the $\Delta c c p A$ mutant compared to the parent strain in LB in the absence of glucose, and of four CcpA- and glucose-dependent genes by Northern blot analyses (Fig. 2). The tested genes showed the same trend in expression by Northern as in the microarray.

\section{CcpA-dependent differential gene expression without glucose addition}

Genes showing an altered expression in the $\Delta c c p A$ mutant compared to the wild-type when growing in LB alone, without glucose addition, are listed in Additional files 1: Genes with lower expression in wild-type versus $\Delta c c p A$ mutant, and 2: Genes with higher expression in wild-type versus $\Delta c c p A$ mutant. These genes made up the largest reg- 

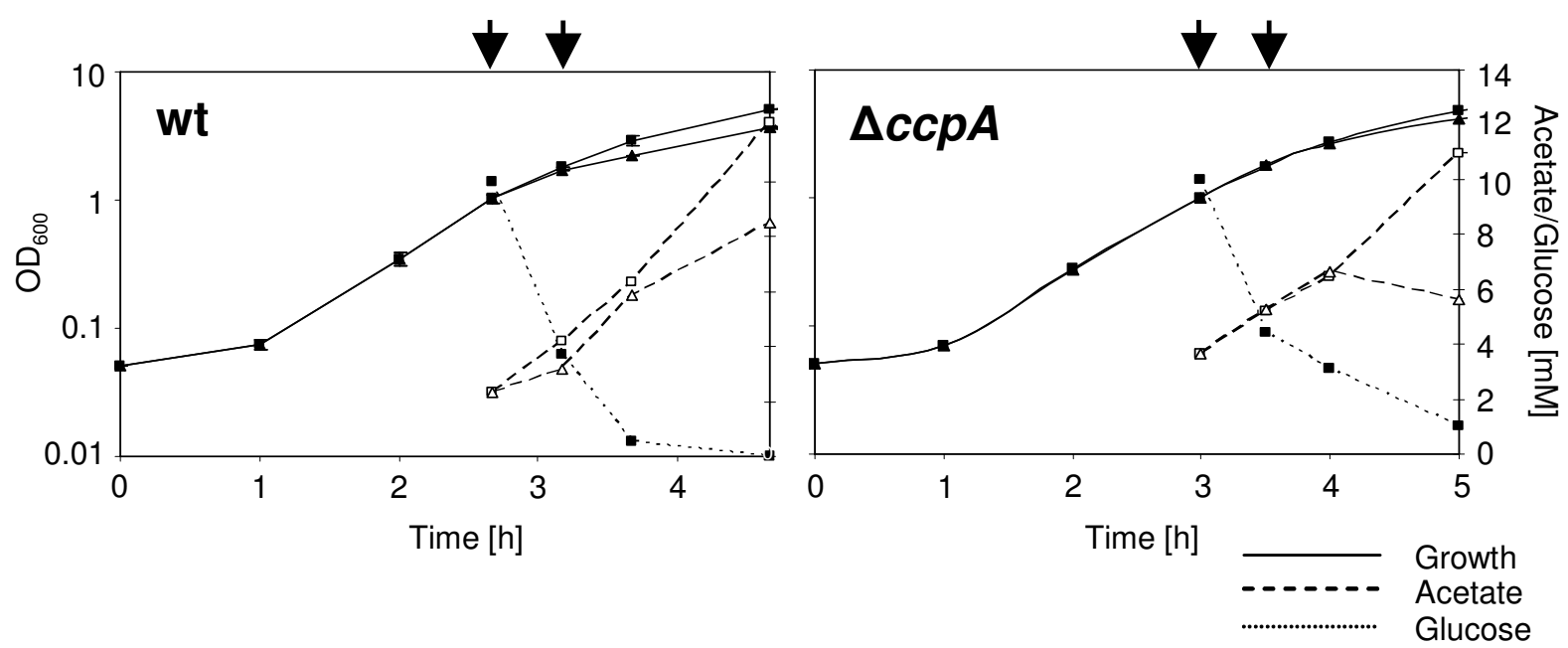

Figure I

Growth, glucose consumption and acetate build-up. Growth, glucose consumption and acetate formation in strain Newman (wt) and its isogenic $\triangle c c p A$ mutant $(\Delta c c p A)$. Cells were grown to an $\mathrm{OD}_{600}$ of I, cultures were split and $10 \mathrm{mM}$ glucose was added to one half of the culture (squares), while the other half remained without glucose (triangles). Cells were sampled at an $\mathrm{OD}_{600}$ of $\mathrm{I}$ and $30 \mathrm{~min}$ after glucose addition for RNA isolation (indicated by arrows). Experiments shown are representative for three independent experiments.

ulatory group found in our study (226 genes). Only a minor part of this group of genes (38 out of 226) contained putative cre-sites in their promoter regions or were part of operons with putative cre-sites, suggesting that CcpA may affect the expression of the majority of these genes indirectly. Such indirect effects may reflect differences in the generation of metabolites due to $\operatorname{csp} A$ inactivation, which might serve as cofactors for the regulation of further genes, and/or to a CcpA-dependent control of regulatory proteins or RNAs. Our findings suggest that glucose-independent effects due to CcpA might play a particularly important role in $S$. aureus. For a better understanding, the genes of this category were grouped into functional classes (Fig. 3A). While unknown proteins rep- resented the largest group (61 genes), this group was followed by proteins of carbon metabolism (26 genes), transport/binding proteins and lipoproteins (25 genes), and proteins of amino acid metabolism ( 19 genes).

\section{Glucose-dependent, CcpA-dependent genes}

All genes found to be subject to regulation by glucose in a CcpA-dependent way are depicted in the Additional files 3: CcpA dependent down-regulation by glucose, and 4: CcpAdependent up-regulation by glucose. For consistency reasons, a few genes which were not meeting the arbitrary threshold, such as SA0605 or SA0299 (indicated by a paragraph), were included, since these genes are part of putative operons and showed a tendency towards regulation. As

Table I: Numbers of $S$. aureus genes subject to regulation by glucose and/or CcpAa

\begin{tabular}{lcc}
\hline Regulatory class $^{\mathrm{b}}$ & Number of genes & Genes associated with putative cre-sites \\
\hline CcpA-dependent in the absence of glucose & $\mathbf{2 2 6}$ & $\mathbf{3 8}$ \\
Lower expression in wild-type & 118 & 28 \\
Higher expression in wild-type & 108 & 10 \\
CcpA- and glucose-dependent & 155 & $\mathbf{4 8}$ \\
Down-regulated & 81 & 38 \\
Up-regulated & 74 & 3 \\
Partially dependent on CcpA & 21 & $\mathbf{3}$ \\
CcpA-independent, but glucose-dependent & 10 & 0 \\
Down-regulated & 10 & 0 \\
Up-regulated & 0 & 0 \\
\hline
\end{tabular}

aA gene was considered to be regulated if transcription was induced or repressed at least two fold

bClasses partly overlap 


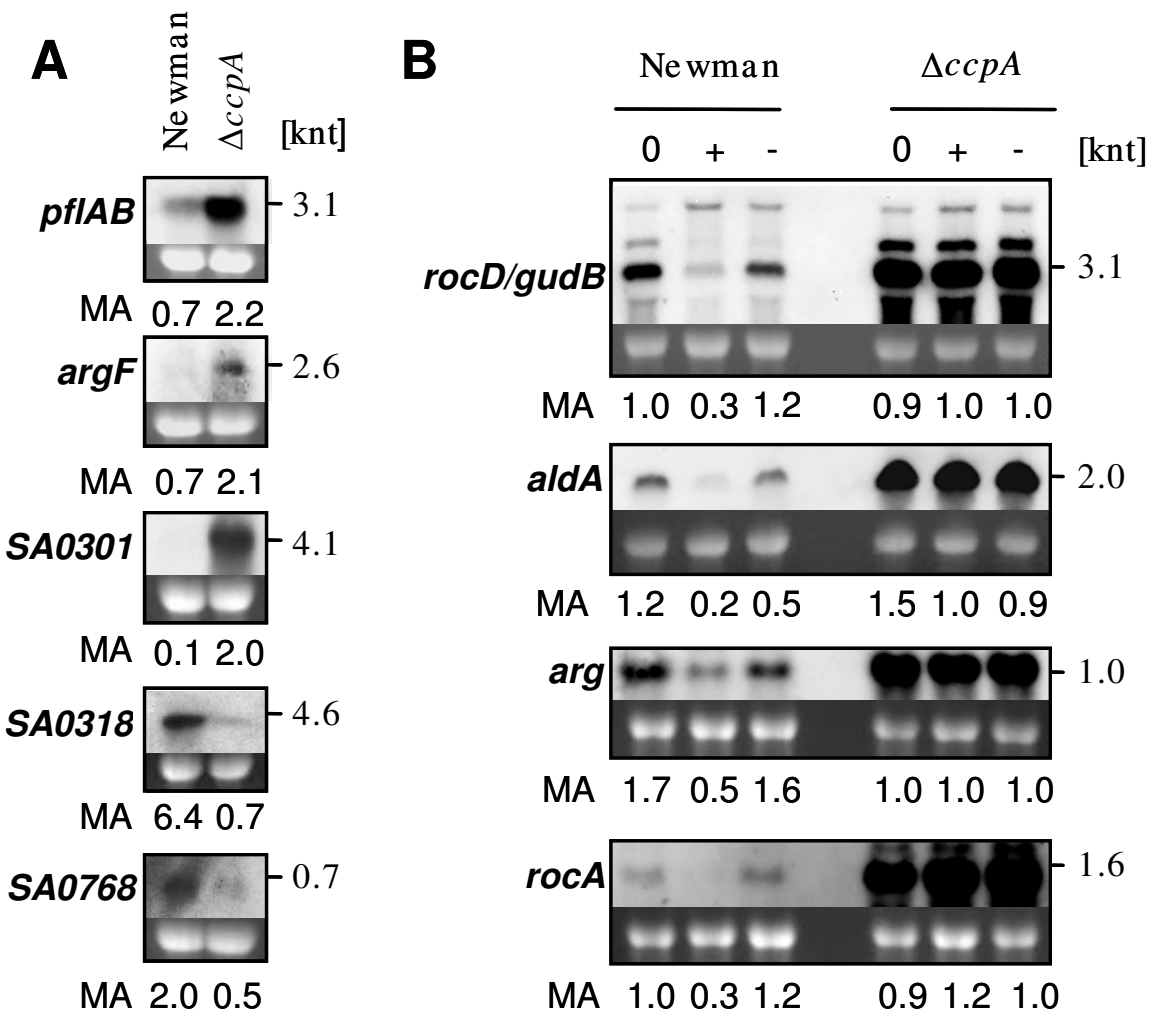

Figure 2

Northern blot analyses of CcpA-dependent genes. A, Transcription of genes showing differential expression in the ccpA mutant in the absence of glucose. Gene expression at an $\mathrm{OD}_{600}$ of $\mathrm{I}$ in strain Newman and its $\Delta c c p A$ mutant is shown. $\mathrm{B}$, Transcription of CcpA-dependent, glucose-dependent genes in strain Newman and its $\triangle$ ccpA mutant. Cells were grown to an $\mathrm{OD}_{600}$ of I, cultures where split and glucose added to one half $(+)$, while the other half remained without glucose (-). RNA was sampled at an $O D_{600}$ of $\mathrm{I}$, and after $30 \mathrm{~min}$. RNA loading is represented by the intensity of the I6S rRNA. Data are representative for at least two independent experiments. MA, microarray data.

before, only a minor part of the affected genes/operons (48 out of 155) contained putative cre-sites in their promoter regions, indicating a direct control by $\mathrm{CcpA}$, while the majority of genes seemed to be controlled by CcpA in a way that did not involve the interaction with an apparent cre-site.

Grouping the regulated genes into functional categories according to the DOGAN annotation [26] and/or KEGG database [27] showed that unknown proteins represented again the largest regulated category (39 genes), followed by transport/binding proteins and lipoproteins (22 genes), metabolism of amino acids (19 genes), and metabolism of carbohydrates (17 genes) (Fig. 3B).

\section{CcpA-independent regulation by glucose}

We found a small group of genes, encoding the 6-phospho-betaglucosidase, the putative ascorbate transportand the lactose-operon, to be regulated by glucose in an apparently CcpA-independent way (Table 2). The lactose operon, reported to be controlled by catabolite repression [28] requires intracellular galactose-6-phosphate for induction [29]. The lack of specific inducer under the conditions used here may have obscured the CcpA-dependent regulatory effects on the lac- and other operons, or mechanisms accounting for CcpA-independent catabolite control may be active [9]. Again, the table includes a few genes not meeting the arbitrary threshold (indicated by a paragraph), which were nevertheless listed, since they are likely to form part of putative operons and showed a tendency towards regulation that was consistent with the other member(s) of these operons.

Glucose-dependent genes regulated by CcpA and additional factors One group of genes showed markedly different regulatory patterns upon glucose addition (Table 3). These patterns might reflect the interplay of two or several regulators acting on the genes/operons, indicating the presence of further glucose-responsive regulatory elements in addition to CcpA. One pattern was characterized by a parallel up- or down-regulation by glucose in wild-type and mutant, but with different ratios, exemplified by trePCR and alsDS. Another set of genes (i.e. pstB or $m t l F$, SA1218-1221, and 


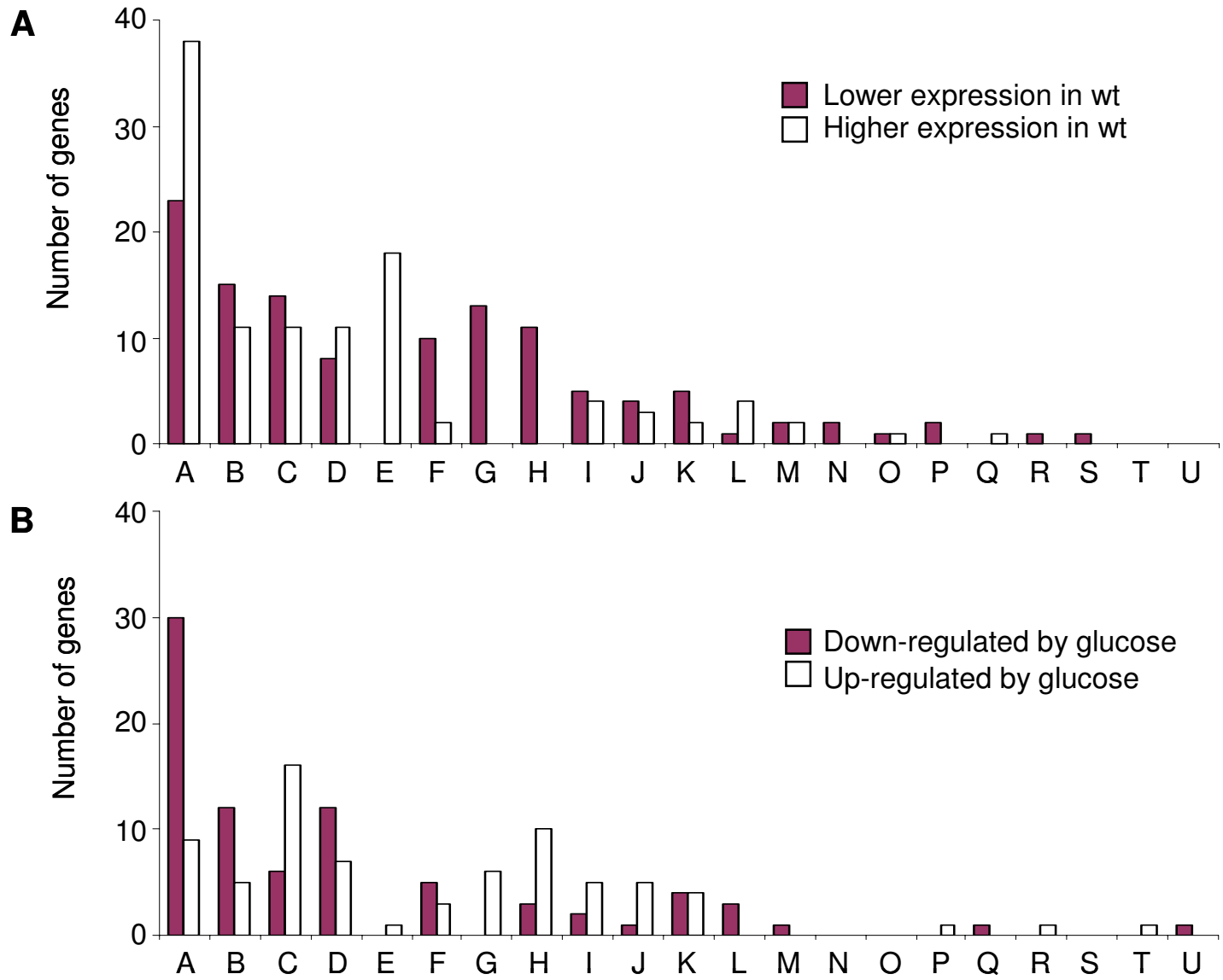

Figure 3

Functional classes of CcpA-dependent genes. Functional classification according to the DOGAN website [26] of genes that were found to be regulated by $\mathrm{Ccp} A$ in a glucose-independent $(A)$ or a glucose-dependent way (B). Categories indicated are: A, Similar to unknown proteins/no similarity; B, Metabolism of carbohydrates and related molecules; C, Transport/binding proteins and lipoproteins; D, Metabolism of amino acids and related molecules; E, Adaption to atypical conditions; F, Pathogenic factors; G, Protein synthesis; $\mathrm{H}$, Metabolism of nucleotides and nucleic acids; I, Metabolism of coenzymes and prosthetic groups; J, Membrane bioenergetics; K, RNA synthesis; L, Metabolism of lipids; M, Miscellaneous; N, Cell wall; O, Detoxification; P, Sensors; Q, Cell division; R, DNA replication; S, Protein folding; T, DNA recombination; U, DNA recombination.

SA2321) showed a divergent glucose-regulation in wildtype and mutant. A third set, represented by the gntRKP operon, the ribHABD operon, SA1961 and SA2434SA2435, differed in expression in response to glucose in the mutant but not in the wild-type.

\section{Metabolic pathways under the control of CcpA}

In $S$. aureus, glucose is mainly catabolized to pyruvate via glycolysis [30] (Fig. 4). The enzymes catalyzing the central parts of glycolysis of $S$. aureus are encoded by five genes: a glyceraldehyde-3-phosphate dehydrogenase (gap), phosphoglycerate kinase $(p g k)$, triosephosphate isomerase (tpi), phosphoglyceromutase (pgm), and enolase (eno). We found that in the presence of glucose, only tpi and $p g k$ were up-regulated by a factor of more than two in a CcpAdependent manner (Fig. 4, Additional file 4: CcpAdependent up-regulation by glucose). The absence of putative cre-sites indicated indirect control by CcpA. The other glycolytic genes also tended to show an up-regulation in transcription in response to glucose, however, below the threshold-level, and this tendency was also observed for the mutant (see Additional file 4: CcpAdependent up-regulation by glucose).

Our microarrays confirmed previous findings [24,31], reporting a glucose-induced CcpA-mediated repression of PEP carboxykinase ( $p c k A$ ) (Fig. 4, Additional file 3: CcpAdependent down-regulation by glucose), which is involved in gluconeogenesis. The presence of a putative cre-site in the promoter region of this gene indicated a direct regulation by CcpA [24,31], which contrasts with findings made in $B$. subtilis, where $p c k A$ was shown to be under indirect control of CcpA [32]. 
The pentose phosphate pathway, an alternative glucose degradation pathway in $S$. aureus [30], provides the cell with NADPH and precursors for biomass, which are needed in many anabolic reactions. gntRKP was the only operon of the pentose phosphate pathway we found to be regulated at least partially by CcpA (Table 3).

When glucose is depleted from the medium, $S$. aureus reintroduces products of carbon overflow, such as acetate or acetoin, into central metabolism $[33,34]$. The genes for acetolactate synthase (alsS) and acetolactate decarboxylase $($ als $D)$, both involved in acetoin production, were upregulated by glucose (Table 3 ). Although up-regulation was found in wild-type and $\Delta c c p A$ mutant, it was three times higher in the wild-type, indicating a substantial contribution of CcpA in alsD and alsS transcription in response to glucose. While the amount of acetate in the medium increased upon glucose addition in both, wildtype and mutant (Fig. 1), we neither observed an increase in transcription of genes encoding proteins being involved in acetate formation (i.e. phosphotransacetylase [pta] and acetate kinase [ackA]), nor of genes with products responsible for acetate and acetoin utilization (i.e. acetyl-CoA synthetase [acsA], acetoin dehydrogenase $[a c u A]$, and the acetoin utilization protein $[a c u C])$.

In the presence of glucose, CcpA repressed several genes of the TCA cycle, including aconitate hydratase (citB), isocitrate dehydrogenase (citC), and citrate synthase (citZ), confirming previous findings [23]. Also succinate dehydrogenase $(s d h B)$, succinyl-CoA synthetase (sucCD), and 2-oxoglutarate dehydrogenase (odhAB) were repressed by glucose in a CcpA-dependent manner (Fig. 4, Additional file 3: CcpA-dependent down-regulation by glucose). The majority of promoter regions of these genes contained a putative cre-site (see Additional file 3: CcpA-dependent down-regulation by glucose), indicating that the TCA cycle is under direct control of CcpA.

The $p d h A B C D$ operon, coding for the pyruvate dehydrogenase complex, which links glycolysis to the TCA cycle by converting pyruvate to acetyl-CoA, was not found to be regulated by CcpA in $S$. aureus.

S. aureus is able to use amino acids as secondary carbon sources. However, this is not necessary in the presence of high amounts of glucose. Accordingly, we found that several genes coding for enzymes of amino acid degradation (rocA, arg, rocD, glnA, hutI, hutU, aldA, ald, gudB, SA1365, SA1366, SA1367) were repressed by glucose in a CcpA-dependent fashion (see Additional file 3: CcpA-dependent down-regulation by glucose). The genes coding for alanine dehydrogenase (ald), aldehyde dehydrogenase (aldA), arginase (arg), and delta-1-pyrroline-5-carboxylate dehydrogenase (rocA) contained putative cre-sites in their promoter regions (see Additional file 3: CcpA-dependent down-regulation by glucose) and might therefore be under the direct control of CcpA. According to our Northern blot findings and previously published microarray data [35], gudB, encoding glutamate dehydrogenase, and rocD, encoding ornithine aminotransferase, seemed to be co-transcribed. Interestingly, this operon contains three putative cre-sites (see Additional

Table 2: Genes/operons with CcpA-independent regulation by glucose

\begin{tabular}{|c|c|c|c|c|c|}
\hline \multicolumn{2}{|r|}{ ID } & \multirow[b]{2}{*}{ common } & \multirow[t]{2}{*}{ Product $^{\mathrm{a}}$} & \multirow{2}{*}{$\begin{array}{l}\text { wt } \\
+/-b\end{array}$} & \multirow{2}{*}{$\begin{array}{l}\text { mut } \\
+/-b\end{array}$} \\
\hline N3I5 & Newman & & & & \\
\hline \multicolumn{6}{|c|}{ Down-regulated by glucose } \\
\hline SA0256 & NWMN_0200 & $b g \mid A$ & 6-phospho-beta-glucosidase & 0.5 & 0.5 \\
\hline SA0318 & NWMN_0322 & & ascorbate-specific PTS system enzyme IIC & 0.1 & 0.3 \\
\hline SA0319 & NWMN_0323 & & similar to PTS system component & 0.2 & 0.2 \\
\hline SA0320 & NWMN_0324 & & similar to PTS transport system IIA component & 0.2 & 0.2 \\
\hline SA032I & NWMN_0325 & & similar to PTS multidomain regulator & 0.3 & 0.2 \\
\hline SAI991 & NWMN_2093 & lacG & 6-phospho-beta-galactosidase & 0.5 & 0.5 \\
\hline SAI992 & NWMN_2094 & lacE & PTS system, lactose-specific IIBC component & 0.5 & 0.4 \\
\hline SAI993 & NWMN_2095 & lacF & PTS system, lactose-specific IIA component & 0.4 & 0.4 \\
\hline SAI994 & NWMN_2096 & $\operatorname{lacD}$ & tagatose-I,6-diphosphate aldolase & 0.5 & 0.4 \\
\hline SAI995 & NWMN_2097 & lacC & tagatose-6-phosphate kinase & $0.6 \S$ & $0.6 \S$ \\
\hline SAI996 & NWMN_2098 & $\operatorname{lacB}$ & galactose-6-phosphate isomerase LacB subunit & 0.5 & 0.4 \\
\hline SAI997 & NWMN_2099 & $\operatorname{lac} A$ & galactose-6-phosphate isomerase LacA subunit & $0.6 \S$ & 0.5 \\
\hline
\end{tabular}

a Cellular main roles are in accordance with the N3I5 annotation of the DOGAN website [26] and/or the KEGG website [27].

b Comparison of gene expression with $(+)$ and without (-) glucose, genes with a $+/$ - glucose ratio of $\leq 0.5$ or $\geq 2$ in the wild-type were considered to be regulated

$\S$ Genes with regulation above threshold, which were included in the list because they were part of a putative operon. 
Table 3: Glucose-dependent genes regulated by CcpA and additional factors 1

\begin{tabular}{|c|c|c|c|c|c|}
\hline & ID & & Product $^{\mathrm{a}}$ & wt & mut \\
\hline N3I5 & Newman & common & & $+/-b$ & $+/-b$ \\
\hline SA0432 & NWMN_0438 & treP & PTS system, trehalose-specific IIBC component & 0.5 & 0.2 \\
\hline SA0433 & NWNM_0439 & treC & alpha-phosphotrehalose & 0.7 & 0.3 \\
\hline SA0434 & NWNM_0440 & treR & trehalose operon repressor & 0.7 & 0.3 \\
\hline SA 1218 & NWNM_1297 & pstB & phosphate $A B C$ transporter, ATP-binding protein (PstB) & 0.5 & 2.6 \\
\hline SAI 219 & NWNM_1298 & & similar to phosphate $A B C$ transporter & 0.4 & 2.7 \\
\hline SAI 220 & NWNM_1299 & & similar to phosphate $A B C$ transporter & 0.3 & 3.7 \\
\hline SAI22I & NWNM_I300 & pstS & thioredoxine reductase & 0.1 & 3.6 \\
\hline SAI586 & NWNM_I659 & $\mathrm{ribH}$ & 6,7-dimethyl-8-ribityllumazine synthase & 0.6 & 2.2 \\
\hline SAI 587 & NWNM_I660 & ribA & riboflavin biosynthesis protein & 0.6 & 1.8 \\
\hline SAI 588 & NWNM_166I & $\operatorname{ribB}$ & riboflavin synthase alpha chain & 0.7 & 2.0 \\
\hline SAI589 & NWNM_I662 & $\operatorname{ribD}$ & riboflavin specific deaminase & 0.7 & 2.0 \\
\hline SAI960 & NWNM_2057 & $m t \mid F$ & PTS system, mannitol specific IIBC component & 6.4 & 0.2 \\
\hline SAI96I & NWNM_2058 & & similar to transcription antiterminator BgIG family & 0.9 & 0.4 \\
\hline SA2007 & NWNM_2110 & als $D$ & alpha-acetolactate decarboxylase & 9.1 & 2.7 \\
\hline SA2008 & NWNM_2III & alsS & alpha-acetolactate synthase & 9.1 & 3.1 \\
\hline SA2293 & NWNM_240I & gntP & gluconate permease & 0.7 & 2.5 \\
\hline SA2294 & NWNM_2402 & gntK & gluconate kinase & 1.6 & 3.7 \\
\hline *SA2295 & NWNM_2403 & gntR & gluconate operon transcriptional repressor & 1.5 & 3.2 \\
\hline SA2321 & NWMN_2432 & & hypothetical protein & 0.1 & 2.5 \\
\hline SA2434 & NWNM_2540 & & PTS system, fructose-specific IIABC component & 1.2 & 0.4 \\
\hline SA2435 & NWNM_254I & pmi & mannose-6-phosphate isomerase & 1.2 & 0.4 \\
\hline
\end{tabular}

'Genes with parallel glucose-mediated regulation in wild-type and mutant but with different ratios, genes with divergent glucose-mediated regulation in wild-type and mutant, and genes with glucose-mediated regulation in the mutant but not in the wild-type

a Cellular main roles are in accordance with the N3I5 annotation of the DOGAN website [26]and/or the KEGG website [27].

b Comparison of gene expression with (+) and without (-) glucose, genes with a $+/$ - ratio of $\leq 0.5$ or $\geq 2$ in the wild-type and the mutant were considered to be regulated)

* Genes containing putative cre-sites

file 3: CcpA-dependent down-regulation by glucose), suggesting a complex transcriptional regulation by CcpA, which could be confirmed by our Northern blot analyses, showing that $r o c D / g u d B$-transcription is largely affected by CcpA in response to glucose. Similarly, aldA, arg, and rocA transcription patterns determined by Northern analyses showed the same tendency as our microarray data (Fig. 2).

Table 4 shows genes coding for transporters or lipoproteins which were regulated by glucose in a CcpA-dependent manner or which were partially controlled by CcpA. Seven of these genes contained putative cre-sites in their promoter regions, or as in the case of SA0186, SA0302, and gntP, belonged to an operon which contained a putative $c r e$-site and were probably under the direct control of CcpA. The up-regulation of the glucose uptake protein homologue (SA2053) may contribute to the rapid glucose consumption observed in the wild-type (Fig. 1). Many putative non-sugar-transporters were found to be regulated by CcpA: Amongst them, the opu-operon, which is preceded by a putative cre-site and consists of opuCAориСB-ориCC-ориCD, coding for a glycine-betaine/carnitine/choline $\mathrm{ABC}$ transporter, acting in osmoprotection [36], was up-regulated by glucose. Interestingly, the same operon is also up-regulated in $f e m A B$ mutants, due to a secondary effect compensating for an impaired cell envelope [37]. S. aureus possesses two systems involved in osmoprotection [36], the second system encoded by the opuD gene did not appear to be regulated by CcpA.

\section{Selected CcpA-affected genes involved in virulence, pathogenicity, stress response and resistance}

Urease is considered to be a virulence factor contributing to pathogenesis in many bacteria [38]. It hydrolyses urea 


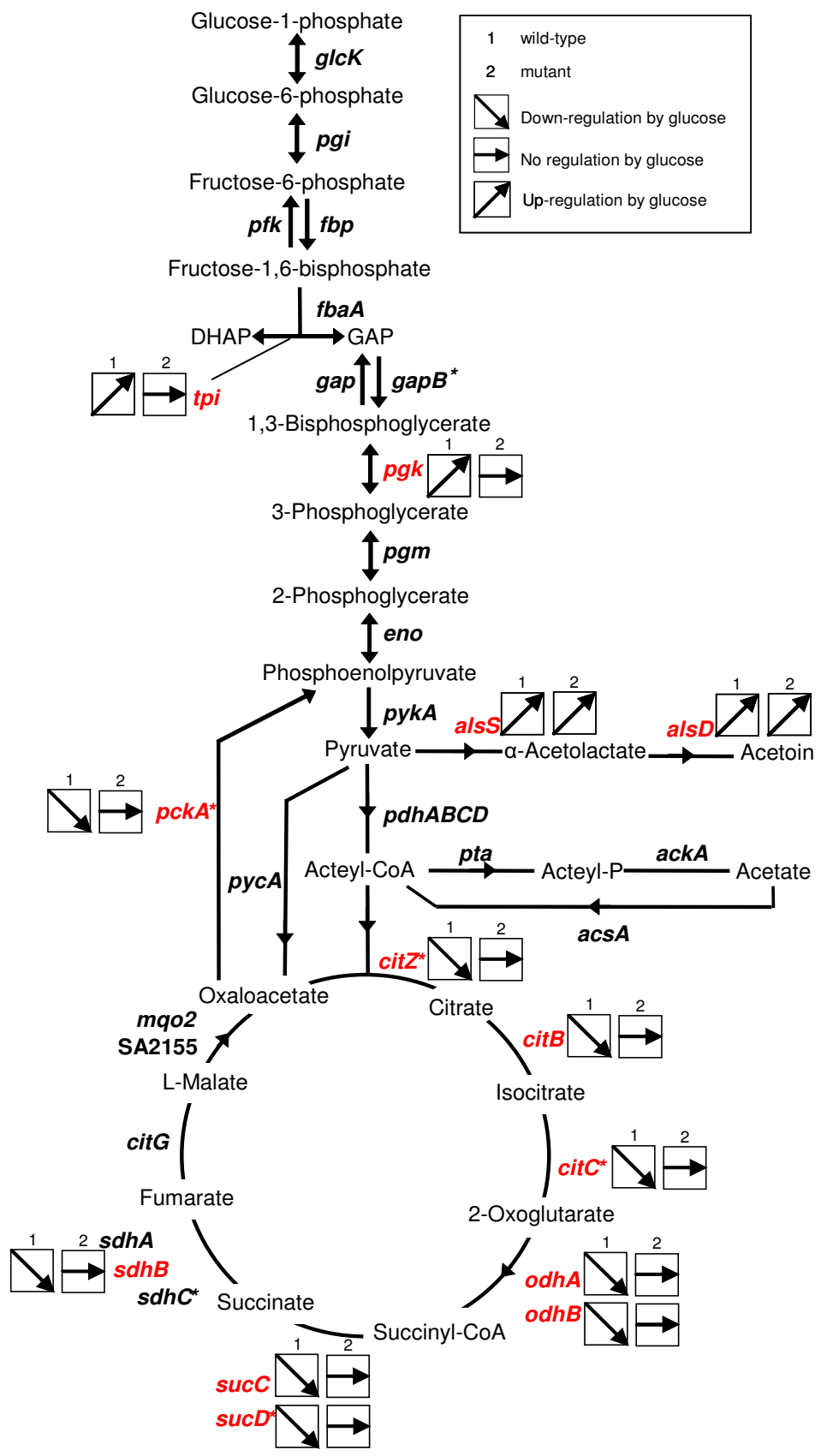

Figure 4

Overview on CcpA- and glucose-dependent genes of glycolysis, gluconeogenesis and TCA cycle. Assignment of genes coding for enzymes of glycolysis, gluconeogenesis and the TCA cycle which are regulated by CcpA. ackA, acetate kinase; $a c s A$, acetyl-CoA synthetase; citB, aconitate hydratase; citC, citrate dehydrogenase; citG, fumarate hydratase; citZ, citrate synthase; eno, enolase; $f b p A$, fructose-bisphosphate aldolase; fbp, fructose-I,6-bisphosphatase; gap, glyceraldehyde-3-phosphate dehydrogenase; gapB, glyceraldehyde-3-phosphate dehydrogenase; glcK, glucokinase; mqo2, malate:quinone-oxidoreductase; odhA, 2-oxoglutarate dehydrogenase component $\mathrm{EI}$; odhB, 2-oxoglutarate dehydrogenase component E2; pckA, phosphoenolpyruvate carboxykinase; $p d h A B C D$, pyruvate dehydrogenase; $p f k$, phosphofructokinase; pgi, glucose-6-phosphate isomerase; pgk, phosphoglycerate kinase; pgm, phosphoglycerate mutase; pycA, pyruvate carboxylase; pykA, pyruvate kinase; SA2I55, malate:quinone-oxidoreductase; sdhA, succinate dehydrogenase; sucC, succinyl-CoA synthetase, beta subunit; sucD, succinylCoA synthetase, alpha subunit; tpi, triose-3-phosphate isomerase. *, genes with putative cre-sites; red, regulated genes. 
into ammonia and carbon dioxide, supplying nitrogen and helping to maintain the $\mathrm{pH}$ stable by the formation of ammonium, allowing the adaptation to environmental changes. We noticed that irrespective of whether glucose was present in the medium or not, the urease-operon expression was higher in the wild-type than in the $\Delta c c p A$ mutant (see Additional file 2: Genes with higher expression in wild-type versus $\Delta c c p A$ mutant). Urease activity assays confirmed the transcriptional findings by showing an increased urease production by the wild-type strain in urea-containing medium compared to the $\Delta c c p A$ mutant (Fig. 5).

We previously observed a CcpA-dependent down-regulation of the protein A encoding gene spa in response to glucose [24], which was confirmed here by our transcriptional analyses (Table 5). Moreover, further genes known or thought to encode proteins being involved in immunomodulating processes, such as the immunodominant antigen A (IsaA), the staphylococcal secretory antigen SsaA and its homologue SA2353, and the eap domain homologue SA0841 where found to be down-regulated by glucose in the wild-type as well (Table 5). Similarly, the atl gene, coding for the bifunctional autolysin, important in primary attachment to glass and polystyrene surfaces [39] and reduced in intermediate glycopeptide resistant strains [40], was down-regulated by glucose in the wild-type strain. This is partially in contrast to previous findings, in which we observed a trend towards stronger atl expression in glucose containing TSB medium in the wild-type in comparison to a $\triangle c c p A$ mutant [23]. However, growth conditions and strains differed between these two studies.

The genes coding for the two-component-system VraSR were found to be up-regulated by glucose in a CcpAdependent manner. This system was reported to regulate the so-called cell wall stress stimulon, a set of genes that is induced in the presence of cell wall damaging agents [41]. Indeed, some of the genes, which were reported to belong to the cell wall stress stimulon of strain Newman [42] were found to be regulated by glucose in a CcpA-dependent manner as well. However, there was no specific correlation between up- and down-regulation in response to glucose and vancomycin.

Surprisingly, $r s b W$, coding for the anti- ${ }^{\circ}$ factor, which forms part of a polycistronic transcript that includes at least the genes rsbUVW and sigB [43], was found to be upregulated two-fold by glucose in the wild-type in a CcpAdependent manner, while none of the other co-transcribed genes of the sigB operon showed changes in expression that were above the threshold (Table 5). Interestingly, similar findings have been made by others as well [44], indicating that the $r s b U V W$-sigB transcripts might be subject to post-transcriptional processes or that further, yet unidentified promoters within the sigB operon might exist, which would lead to increased $r s b W$ transcription.

The gene coding for the fibronectin binding protein $\mathrm{B}$ $(f n b B)$, was up-regulated in the wild-type by glucose. Although this protein is truncated and not functional in strain Newman $[45,46]$, it might be regulated by CcpA in strains where it is functional, suggesting, that CcpA may affect also adherence and host cell invasion [47].

The microarray data confirmed previously published data, in which we found $c i d A$ transcription to be higher in the wild-type than in the $\triangle c c p A$ mutant in the presence of glucose [23]. CidA, controlling cell lysis and the release of extracellular DNA (eDNA), was shown to contribute to biofilm formation [48], which is strongly induced in the presence of glucose [23].

\section{Differential analysis of the cytoplasmic proteome of wild- type and $\triangle$ ccpA mutant}

To complement our transcriptional data, we also compared the cytoplasmic proteome of the wild-type (Newman) and its isogenic $\triangle c c p A$ mutant grown in buffered LB medium in the presence and absence of glucose. The protein patterns under both conditions were compared and proteins, whose amounts were affected by the addition of glucose, were identified by mass spectrometry.

In the presence of glucose, increased amounts of components of the glycolytic pathway such as Pfk, Tpi, Pgk, Pgm, Eno, Gap and PykA were observed in the wild-type (Fig. 6A). Proteins of gluconeogenesis, namely the gluconeogenic glyceraldehyde-3P-dehydrogenase (GapB), fructose bisphosphatase (Fbp), and PEP carboxykinase (PckA) were present at lower levels in the presence of glucose in the wild-type, while in the mutant, the amounts were not altered in response to glucose (Fig. 6A). Also the production of acetyl-CoA-synthetase (AcsA) was clearly downregulated by glucose in a CcpA-dependent manner (Fig. $6 B)$.

In line with the transcriptional findings, the level of TCA cycle enzymes detetctable on 2D gels (CitZ, CitB, CitC, OdhA/B, SucC, SucD, SdhA, CitG) was found to be clearly reduced in the wild-type after addition of glucose (Fig. $6 B)$.

S. aureus encodes two malate:quinone oxidoreductases: Mqo2 and SA2155. While the amount of Mqo2 was not affected by glucose, the amount of SA2155 as the other TCA cycle enzymes was strongly reduced (data not shown). Interestingly, pyruvate carboxylase (PycA), which is needed to replenish the pool of TCA intermediates, was 
Table 4: CcpA-dependent genes coding for transport/binding proteins and lipoproteins regulated by glucose

\begin{tabular}{|c|c|c|c|c|c|}
\hline \multicolumn{2}{|r|}{ ID } & \multirow[b]{2}{*}{ common } & \multirow[t]{2}{*}{ Product ${ }^{\mathrm{a}}$} & \multirow{2}{*}{$\begin{array}{l}\text { wt } \\
+/-b\end{array}$} & \multirow{2}{*}{$\begin{array}{l}\text { mut } \\
+/-\mathrm{b}\end{array}$} \\
\hline N315 & Newman & & & & \\
\hline \multicolumn{6}{|c|}{ Down-regulated by glucose } \\
\hline SAOIOO & NWMN_0049 & & similar to $\mathrm{Na}+\mathrm{P}_{\mathrm{i}}$-cotransporter & 0.2 & 1.7 \\
\hline *SA0186 & NWNM_0I36 & & sucrose-specific PTS tranporter IIBC component protein & 0.4 & 1.2 \\
\hline *SA0302 & NWNM_0255 & & probable pyrimidine nucleoside transport protein & 0.4 & 1.8 \\
\hline SAI848 & NWNM_1950 & $n r g A$ & probable ammonium transporter & 0.4 & 0.8 \\
\hline SA2226 & NWNM_2337 & & similar to D-serine/D-alanine/glycine transporter & 0.2 & 0.9 \\
\hline SA2227 & NWNM_2337 & & amino acid $A B C$ transporter homologue & 0.1 & 0.9 \\
\hline \multicolumn{6}{|c|}{ Up-regulated by glucose } \\
\hline SA0I 66 & NWNM_0II6 & & similar to nitrate transporter & 2.8 & 1.1 \\
\hline SA0167 & NWNM_0II7 & & similar to membrane lipoprotein SrpL & 2.8 & 1.6 \\
\hline SA0168 & NWNM_0II8 & & similar to probable permease of $A B C$ transporter & 2.3 & 1.1 \\
\hline SA0214 & NWMN_0I58 & uhpT & hexose phosphate transport protein & 2.1 & I.I \\
\hline SA0335 & NWMN_0340 & & twin-arginine translocation protein $\mathrm{Tat} A$ & 2.2 & 1.4 \\
\hline SA0374 & NWNM_0379 & pbuX & xanthine permease & 7.2 & I.I \\
\hline *SA0655 & NWNM_0669 & fruA & fructose specific permease & 2.4 & 1.3 \\
\hline SA0769 & NWNM_0780 & & D-methionine transport system ATP-binding protein & 2.4 & 0.8 \\
\hline SA0770 & NWNM_078I & & D-methionine transport system permease & 2.4 & 1.0 \\
\hline SAI270 & NWNM_I347 & & similar to amino acid permease & 2.0 & 1.1 \\
\hline SA2053 & NWNM_2158 & & glucose uptake protein homologue & 2.5 & 1.2 \\
\hline SA2234 & NWMN_2344 & opuCD & probable glycine betaine/carnitine/choline $A B C$ transporter (membrane part) $O p u C D$ & 1.6 & 1.2 \\
\hline SA2235 & NWMN_2345 & opuCC & glycine betaine/carnitine/choline $A B C$ transporter (osmoprotection) OpuCC & 1.9 & 1.2 \\
\hline SA2236 & NWMN_2346 & opuCB & probable glycine betaine/carnitine/choline $A B C$ transporter (membrane part) OpuCB & 1.9 & 1.1 \\
\hline *SA2237 & NWMN_2347 & opuCA & glycine betaine/carnitine/choline $A B C$ transporter (ATP-binding) OpuCA & 2.6 & 1.0 \\
\hline SA2239 & NWNM_2349 & & similar to amino acid transporter & 2.2 & 1.1 \\
\hline SA2443 & NWMN_2549 & & similar to accessory secretory protein Asp3 & 2.0 & 1.2 \\
\hline SA2444 & NWMN_2550 & & similar to accessory secretory protein Asp2 & 2.3 & 1.3 \\
\hline \multicolumn{6}{|c|}{ Partially controlled by CcpA } \\
\hline SA0432 & NWMN_0438 & treP & PTS system, trehalose-specific IIBC component & 0.5 & 0.2 \\
\hline SA 1218 & NWNM_I297 & pstB & phosphate $A B C$ transporter, ATP-binding protein (PstB) & 0.5 & 2.6 \\
\hline SAI219 & NWNM_1298 & & similar to phosphate $A B C$ transporter & 0.4 & 2.7 \\
\hline SAI 220 & NWNM_1299 & & similar to phosphate $A B C$ transporter & 0.3 & 3.7 \\
\hline SAI960 & NWNM_2057 & $m t / F$ & PTS system, mannitol specific IIBC component & 6.4 & 0.2 \\
\hline *SA2293 & NWNM_240I & gntP & gluconate permease & 0.7 & 2.5 \\
\hline SA2434 & NWNM_2540 & & PTS system, fructose-specific IIABC component & 1.2 & 0.4 \\
\hline
\end{tabular}

a Cellular main roles are in accordance with the N3I5 annotation of the DOGAN website [26] and/or the KEGG website [27].

bComparison of gene expression with $(+)$ and without (-) glucose, genes with a $+/$ - glucose ratio of $\leq 0.5$ or $\geq 2$ in the wild-type were considered to be regulated

*Genes containing putative cre-sites 
found to be increased by glucose in the wild-type but not in the mutant (Fig. 6B).

In contrast to B. subtilis $[32,49]$, the expression of AckA and Pta, being involved in the overflow metabolism, was not affected by CcpA and/or glucose (data not shown). Neither could we detect an effect of CcpA or glucose on the amount of the pentose phosphate pathway-enzymes, suggesting that considerable differences between $S$. aureus and $B$. subtilis exist in the CcpA-dependent regulation of the pentose phosphate pathway and carbon overflow [32].

In accordance with our microarray data, several enzymes of amino acid degradation (RocA, RocD, GudB, Ald, AldA, GlnA, and Dho) were repressed by glucose in a CcpAdependent manner (Fig. 6C).

\section{Conclusion}

The catabolite control protein A is likely to regulate transcription either directly, by binding to catabolite responsive elements (cre-sites), or indirectly by affecting the expression of regulatory molecules which in turn alter the transcription of their target genes. We previously observed that CcpA of $S$. aureus affects the expression of RNAIII [24], the effector molecule of the agr locus, and one of the major regulators of virulence determinant production of this organism [50]. Aiming at the identification of genes that are directly affected by CcpA in response to glucose, we chose an experimental setup in which we gave a glucose-impulse to exponentially growing wild-type and $\triangle c c p A$ mutant cells and analyzed the effect 30 min (transcriptome) and $60 \mathrm{~min}$ (proteome) after the glucose addition. While this strategy was likely to reduce putative sideeffects, such as the CcpA-dependent regulation of RNAIII expression or $\mathrm{pH}$-effects, which in turn would have a sig-

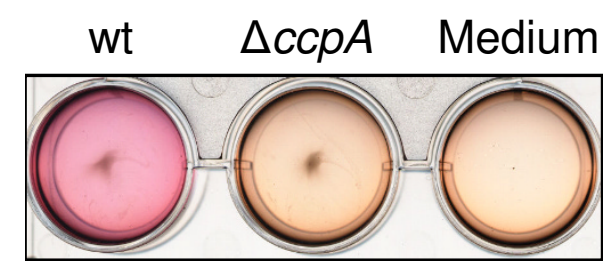

\footnotetext{
Figure 5

Urease production. Urease production in urea-containing medium. The increase in $\mathrm{pH}$ resulting from the cleavage of urea is indicated by a purple colour. wt, strain Newman; $\triangle c c p A$, strain Newman $\triangle c c p A$.
}

nificant effect on the transcriptional and proteomic profiles, it also limited this study to detect only short-term effects of CcpA in response to glucose. It did neither allow the identification of the glucose-induced long-term effects of CcpA on the transcriptome, nor the effect of CcpA on the transcription of genes that are predominantly expressed during the later stages of growth. Thus, one particular consequence of our strategy might have been the overrepresentation of genes/operons found to be affected by the $c c p A$ inactivation in the absence of glucose, which contrasts with findings made in B. subtilis [50], where the glucose-induced effect of CcpA on the transcriptome clearly exceeded the number of genes that were affected by CcpA in a glucose-independent manner [50]. It is feasible that the number of genes being affected by CcpA in $S$. aureus in response to glucose would be higher if a later time-point for the glucose-impulse and/or the analysis would have been chosen, or if appropriate inducers of regulated operons had been present under the conditions analyzed. Another surprising observation that we encountered was the high degree of genes found to be affected by CcpA in a glucose-dependent manner that lacked an apparent cre-site (107 out of 155). This suggests to us that the $S$. aureus CcpA might regulate transcription on a significant level in a way that does not require binding to $\mathrm{cre}$. Changes in the metabolite content and secondary regulatory elements in the $\triangle c c p A$ mutant may be possible explanations. Further, CcpA might bind to a cre consensus, which is composed much broader than the one used by us in this study for the identification of putative cre-sites.

In general, overall induction or repression levels of CcpA were low, showing mostly values around the threshold level of 2 and 0.5, respectively. However, inactivation of $\operatorname{ccp} A$ still leads to drastic alteration in the transcriptome and the proteome of the bacterium, affecting not only major metabolic pathways, but also resistance, virulence and biofilm formation [22-24], which are properties contributing to the adaptation to environmental stress. However, the impact of catabolite repression on staphylococcal virulence in the host can not be predicted by the in vitro data and needs to be assessed experimentally. Environmental conditions, carbon sources, pH etc. differ strongly upon the site of infection and underlying diseases, such as diabetes.

Although overall regulation of central carbon metabolism mediated by CcpA was found to be similar to the one in the model organism $B$. subtilis, the extent to which this control was exerted seemed to differ in some aspects between these two bacteria. CcpA regulation of $S$. aureus seemed to differ in terms of overflow metabolism from $B$. subtilis, since in addition to alsS, pta and ackA where found to be regulated by glucose in a CcpA-dependent way in $B$. subtilis $[34,51,52]$, but not in $S$. aureus. Also the genes 
Table 5: Regulators and factors involved in virulence and/or resistance subject to regulation by CcpA and glucose

\begin{tabular}{|c|c|c|c|c|c|}
\hline \multicolumn{2}{|r|}{ ID } & \multirow[b]{2}{*}{ common } & \multirow[t]{2}{*}{ Product ${ }^{\mathrm{a}}$} & \multirow{2}{*}{$\begin{array}{l}\text { wt } \\
+/-b\end{array}$} & \multirow{2}{*}{$\begin{array}{l}\text { mut } \\
+/ \text {-b }\end{array}$} \\
\hline N315 & Newman & & & & \\
\hline \multicolumn{6}{|c|}{ Glucose-dependent regulation by CсpA } \\
\hline \multicolumn{6}{|c|}{ Down-regulated by glucose } \\
\hline *SA0I07 & NWNM_0055 & spa & immunoglobulin $\mathrm{G}$ binding protein A precursor & 0.2 & I.I \\
\hline SA0620 & NWNM_0634 & & secretory antigen SsaA homologue & 0.4 & 0.9 \\
\hline SA084I & NWNM_085I & & similar to cell surface protein Map-w & 0.4 & 0.9 \\
\hline SA0905 & NWNM_0922 & atl & autolysin ( $\mathrm{N}$-acetylmuramyl-L-alanine amidase and endo-b- $\mathrm{N}$-acetylglucosaminidase) & 0.4 & 1.1 \\
\hline SA2353 & NWNM_2466 & & similar to secretory antigen precursor SsaA & 0.5 & 1.0 \\
\hline SA2356 & NWNM_2469 & is $a A$ & immunodominant antigen $\mathrm{A}$ & 0.4 & 0.8 \\
\hline \multicolumn{6}{|c|}{ Up-regulated by glucose } \\
\hline SAIOIO & NWNM_1076 & & similar to exotoxin 4 & 2.3 & 0.6 \\
\hline SAI700 & NWNM_I822 & vraR & two-component response regulator & 2.2 & 0.8 \\
\hline SAI70I & NWNM_I823 & vraS & two-component sensor histidine kinase & 2.5 & 0.7 \\
\hline SAI869 & NWNM_1970 & $\operatorname{sig} B$ & sigma factor $B$ & 1.7 & 1.0 \\
\hline SAI870 & NWNM_1971 & rsbW & anti-sigmaB factor & 2.2 & 1.1 \\
\hline SAI87I & NWNM_1972 & $r s b V$ & anti-sigmaB factor antagonist & 1.3 & 0.9 \\
\hline SAI872 & NWNM_1973 & $r s b U$ & sigmaB regulation protein $\mathrm{RsbU}$ & 0.9 & 0.7 \\
\hline SA2290 & NWNM_2397 & $f n b B$ & fibronectin-binding protein homologue & 2.6 & 0.9 \\
\hline *SA2329 & NWNM_2440 & cidA & murein hydrolase regulator & 3.5 & 1.4 \\
\hline
\end{tabular}

a Cellular main roles are in accordance with the N3I5 annotation of the DOGAN website [26] and/or the KEGG website [27].

b Comparison of gene expression with $(+)$ and without (-) glucose, genes with a $+/$ - glucose ratio of $\leq 0.5$ or $\geq 2$ in the wild-type were considered to be regulated

c Comparison of gene expression of wild-type (wt) and $\Delta \mathrm{ccpA}$ mutant (mut) at OD600 I (T0) and 30 min later (T30). genes with a wt/mut ratio of $\leq 0.5$ or $\geq 2$ were considered to be regulated.

* Genes containing putative cre-sites

responsible for acetoin utilization (i.e. acetoin dehydrogenase $[a c u A]$, and the acetoin utilization protein $[a c u C])$, where regulated in a CcpA-dependent manner in B. subtilis [53], but not in $S$. aureus. These genes may however be regulated at a later time point during growth. Another difference was the regulation of the $p d h A B C D$ genes, coding for pyruvate dehydrogenase, which were activated by glucose in B. subtilis but not in S. aureus [32]. Moreover, we found no CcpA-dependent regulation of glutamate synthase ( $g l t B D$ ), which catalyses the conversion of glutamate to 2oxoglutarate, again in contrast to the findings in B. subtilis, in which the transcription of these genes is induced in response to glucose by CcpA [2]. Also different to B. subtilis was the finding that none of the genes devoted to branched-chain amino acids where induced by the presence of glucose in S. aureus [54-56]. However, in a transcriptome analysis over time, Lulko et al. [5] only observed CcpA-mediated regulation of these genes in the late-exponential growth (transition) phase in B. subtilis.
Thus, it is possible, that also in $S$. aureus these genes might be regulated by glucose in a CcpA-dependent manner at a later growth phase.

\section{Methods}

\section{Bacterial strains and growth conditions}

$S$. aureus Newman [57] and its isogenic $\Delta c c p A$ mutant MST14 [24] were grown in LB medium buffered with 50 mM HEPES ( $\mathrm{pH} 7.5$ ) in Erlenmeyer flasks with a culture to flask volume of $1: 5$ under vigorous agitation at $37^{\circ} \mathrm{C}$ to an optical density $\left(\mathrm{OD}_{600}\right)$ of 1.0. One half of the culture was transferred to a new Erlenmeyer flask and glucose was added to a final concentration of $10 \mathrm{mM}$, while the other half remained without glucose. Samples for microarray analysis were taken at $\mathrm{OD}_{600}$ of 1.0 (T0) and after $30 \mathrm{~min}$ utes (T30). Total RNA was extracted as previously described $[58,59]$. For proteome analysis cells were grown with a culture to flask volume of 1:10 under vigorous agitation until an $\mathrm{OD}_{600}$ of 1.0 and glucose was added to one 

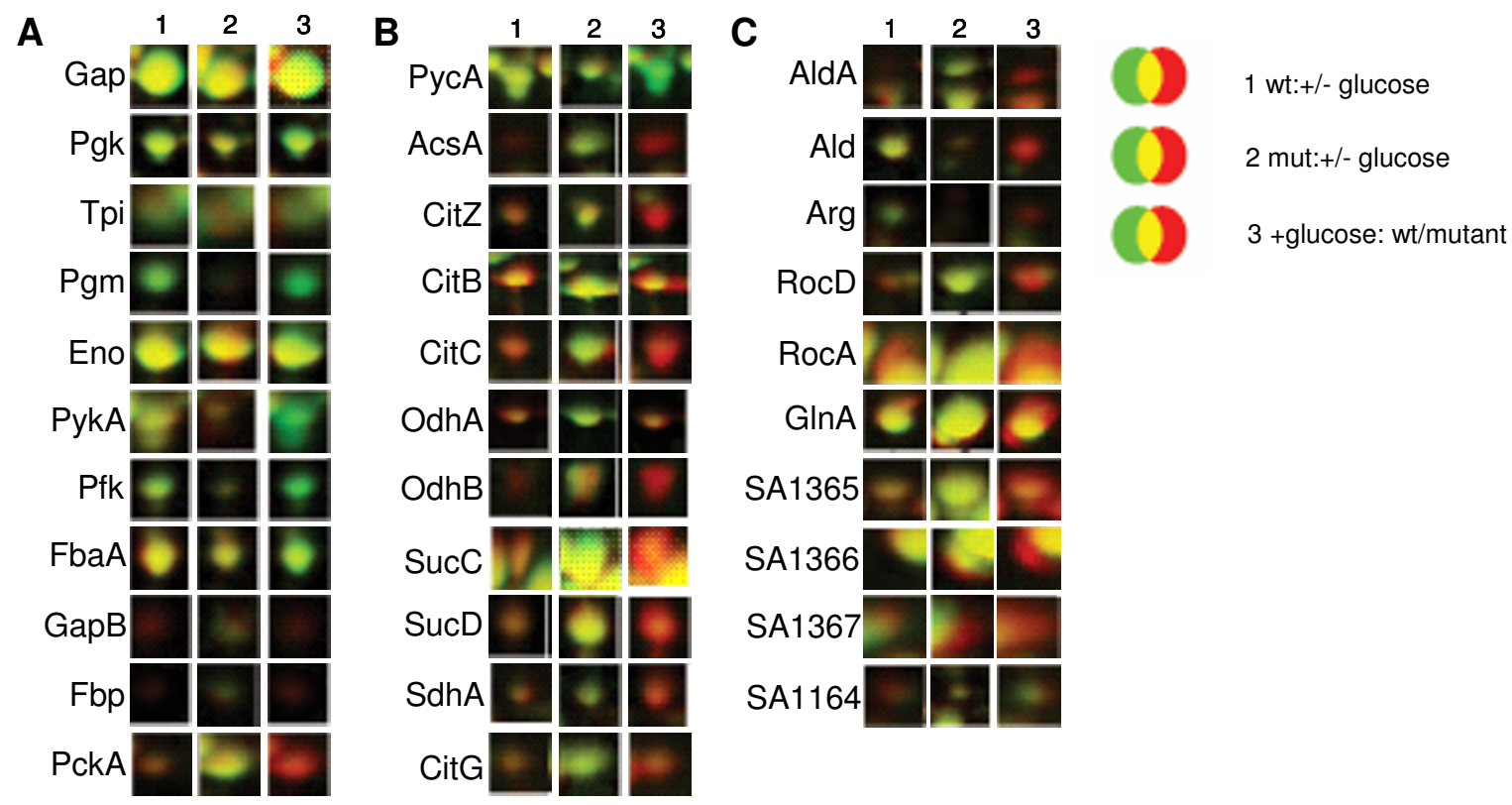

Figure 6

Amounts of selected proteins representing different branches of metabolism. A, glycolysis/gluconeogenesis; B, TCA cycle; and $\mathrm{C}$, amino acid degradation. Differential protein amounts I $\mathrm{h}$ after addition of glucose to exponentially growing cells are shown. The protein levels in the wild-type (I) and mutant (2) in the presence of glucose (green) were compared with the protein levels in the absence of glucose (red). In addition, the protein levels in the presence of glucose (3) in the wild-type (green) were compared to those in the mutant (red).

half of the culture. To allow protein accumulation, samples were taken 60 min afterwards from both, the culture to which glucose was added, and the culture which remained without glucose.

\section{Microarray design and manufacturing}

The microarray was manufactured by in situ synthesis of 10'807 different oligonucleotide probes of 60 nucleotides length (Agilent, Palo Alto, CA, USA), selected as previously described [60]. It covers approximately 99\% of all ORFs annotated in strains N315 and Mu50 [61], MW2 [62] and COL [63] including their respective plasmids [59]. Extensive experimental validation of this array has been described previously, using CGH, mapping of deletion, specific PCR and quantitative RT-PCR [60,64].

\section{Expression microarrays}

DNA-free total RNA was obtained after DNase treatment on RNeasy columns (Qiagen) [58,59]. The absence of remaining DNA traces was evaluated by quantitative PCR (SDS 7700; Applied Biosystems, Framing-ham, MA) with assays specific for $16 \mathrm{~s}$ rRNA [58,59]. Batches of $8 \mu \mathrm{g}$ total S. aureus RNA were labelled by Cy-3 or Cy-5 dCTP using the SuperScript II (Invitrogen, Basel, Switzerland) following manufacturer's instructions. Labelled products were purified onto QiaQuick columns (Qiagen) and mixed with $250 \mu$ l Agilent hybridization buffer, and then hybrid- ized at a temperature of $60^{\circ} \mathrm{C}$ for $17 \mathrm{~h}$ in a dedicated hybridization oven (Robbins Scientific, Sunnyvale, CA, USA). Slides were washed with Agilent proprietary buffers, dried under nitrogen flow, and scanned (Agilent, Palo Alto, CA, USA) using 100\% PMT power for both wavelengths.

\section{Microarray analysis}

Fluorescence intensities were extracted using the Feature extraction $^{\mathrm{TM}}$ software (Agilent, version 8). Local background-subtracted signals were corrected for unequal dye incorporation or unequal load of labelled product. The algorithm consisted of a rank consistency filter and a curve fit using the default LOWESS (locally weighted linear regression) method. Data consisting of two independent biological experiments were analyzed using GeneSpring 7.3 (Agilent). An additional filter was used to exclude irrelevant values. Background noise of each experiment was evaluated by computing the standard deviation of negative control intensities. Features whose intensities were smaller than the standard deviation value of the negative controls in all the measurements were considered as inefficient hybridization and discarded from further analysis [64]. Fluorescence values for genes mapped by 2 probes or more were averaged. Statistical significance of differentially expressed genes was identified by variance analysis (ANOVA) [59,65], performed using GeneSpring, 
including the Benjamini and Hochberg false discovery rate correction (5\%). A gene was considered to be regulated by glucose and/or CcpA if transcription was induced or repressed at least two fold. Microarray data were submitted to the GEO database with accession numbers GPL3931 and GSE12614 for the complete experimental data set.

\section{Evaluation of the microarray data}

Several classes of effects could be observed. Genes, which showed differences in total transcriptome between wildtype and mutant in the absence of glucose at both time points, e.g. $\mathrm{OD}_{600}$ of 1 (T0) and after $30 \mathrm{~min}$ (T30), were considered to be CcpA-dependent, but glucose-independent. When a difference was only observed at one of the two time points or the gene was up-regulated at one and down-regulated at the other time point, it was assumed to have fluctuating expression patterns and was not considered in this study. Genes with a differential expression upon glucose addition in the wild-type but not in the $\triangle c c p A$ mutant were considered to be strictly CcpA-dependent. Changes occurring in parallel in the wild-type and the mutant were considered to be due to glucose, but CcpAindependent. A last group comprised genes, which were found to be affected in their expression in response to glucose in both wild-type and mutant, but with differing ratios, or genes, which showed no regulation in the wildtype, but regulation in the mutant upon glucose addition. This group of genes was considered to be controlled by CcpA and other regulatory proteins at the same time.

For a better interpretation, the organization of genes in putative operons was deduced from the transcriptional profiles of adjacent genes over time according to previous microarrays [35] and by searching for putative terminator sequences using TransTerm [66].

\section{Northern blot analyses}

For Northern blot analysis cells were centrifuged for $2 \mathrm{~min}$ at $12,000 \times \mathrm{g}$ and cell-sediments snap-frozen in liquid nitrogen. RNA isolation and Northern blotting were performed as described earlier [67]. Primer-pairs are shown in Additional file 5: Primers used for the construction of DIG-labelled DNA probes. All Northern blot analyses were performed at least twice on independently isolated RNA samples.

\section{Identification of putative S. aureus cre-sites}

Regulated genes were analyzed by screening for putative cre-sites using the B. subtilis consensus sequence (WWTGNAARCGNWWWCAWW) suggested by Miwa et $a l .2000$ [7]. Being aware that diverse cre-site consensi have been published $[7,8,68-70]$, we allowed up to two mismatches in the staphylococcal cre candidates. To constrict the cre- sites identified, we evaluated the presence of palindromic parts.

Preparation of cytoplasmic proteins for two-dimensional (2D) polyacrylamide gel electrophoresis (PAGE)

Cells of $40 \mathrm{ml}$ culture were harvested on ice and centrifuged for $5 \mathrm{~min}$ at $7000 \mathrm{~g}$ and $4{ }^{\circ} \mathrm{C}$. Cells were washed three times with ice-cold TE ( $10 \mathrm{mM}$ Tris, $1 \mathrm{mM}$ EDTA, $\mathrm{pH}$ 7.5 ) and resuspended in $1.1 \mathrm{ml}$ TE buffer. For mechanical disruption, the cell suspension was transferred to screwcap microtubes (Sarstedt, Germany) containing $500 \mu \mathrm{l}$ of glass beads (diameter $0.10-0.11 \mathrm{~mm}$, Sartorius, Goettingen, Germany). Cells were disrupted by homogenization using a Ribolyser (Thermo Electron Corporation, USA) at $6.5 \mathrm{~m} / \mathrm{s}$ for 35 seconds. The lysate was centrifuged for 25 $\min$ at $21^{\prime} 000 \times g\left(4^{\circ} \mathrm{C}\right)$. In order to remove membrane fragments and insoluble proteins, the centrifugation step was repeated for $45 \mathrm{~min}$ at $21,000 \times g\left(4^{\circ} \mathrm{C}\right)$. The protein concentration was determined using Roti Nanoquant (Roth, Germany), and the protein solution was stored at $20^{\circ} \mathrm{C}$.

\section{Analytical and preparative 2D-PAGE}

2D-PAGE was performed using the immobilized $\mathrm{pH}$ gradient (IPG) technique described previously [71]. In the first dimension, the protein samples $(300 \mu \mathrm{g})$ were separated on IPG strips (GE-Healthcare, Little Chalfont, United Kingdom) in the $\mathrm{pH}$ range of 4 to 7 . The proteins were stained with colloidal Coomassie Brillant Blue [72]. The stained gels were scanned with a light scanner with integrated transparency unit (Quatographic, Braunschweig, Germany).

\section{Protein identification by mass spectrometry}

For identification of proteins by MALDI-TOF-MS, Coomassie stained protein spots were cut from gels using a spot cutter (Proteome WorkTM) with a picker head of 2 $\mathrm{mm}$ and transferred into 96-well microtiter plates. Digestion with trypsin and subsequent spotting of peptide solutions onto the MALDI targets were performed automatically in the Ettan Spot Handling Workstation (GE-Healthcare, Little Chalfont, United Kingdom) using a modified standard protocol [73]. MALDI-TOF-MS analyses of spotted peptide solutions were carried out on a Proteome-Analyzer 4700 (Applied Biosystems, Foster City, CA, USA). The spectra were recorded in a reflector mode in a mass range from 900 to $3700 \mathrm{Da}$. Automatic or manual calibration was performed as described by [73]. After calibration, the peak lists were created using the "peak to mascot" script of the 4700 ExplorerTM software. The resulting peak lists were analyzed by using the mascot search engine (Matrix Science, London, UK), GPMAW 4.1 (Lighthouse data). The annotation of S. aureus N315 was used for protein identification and denotation. Peptide 
mixtures that yielded at least twice a Mowes score of at least 50 and a sequence coverage of at least 30\% were regarded as positive identifications. Proteins that failed to exceed the $30 \%$ sequence coverage cut-off were subjected to MALDI-MS/MS [73]. Database searches were performed using the Mascot search engine with the protein databases of $S$. aureus strain N315.

\section{Protein quantitation approaches}

The 2D gel image analysis was performed with the software "Delta2D" (DECODON GmbH, Greifswald, Germany). Three different data sets were analyzed in order to screen for differences in the amount of cytoplasmic proteins identified on 2D gels.

\section{Detection of glucose, acetate and lactate}

The concentrations of glucose, acetate and lactate in the supernatants were determined using commercially available kits (Boehringer) according to the manufacturer's instructions.

\section{Urease assay}

McFarland 0.5-standard cell suspensions were diluted 100-fold in urea medium [74] and incubated in 12-well plates at $37^{\circ}$ for 24 hours. In parallel, colony forming units $(\mathrm{cfu} / \mathrm{ml})$ were determined.

\section{Authors' contributions}

KS experimentally validated the microarray data, performed computational analyses of cre-sites, Northern blot analyses, urease assays, contributed to the interpretation of the results, and drafted the manuscript. SM confirmed some of the Northern blot experiments and the urease assays. PF of the group of JS carried out the microarrays and performed statistical analyses. SE and CK performed the proteome analysis. $\mathrm{MB}$ and $\mathrm{BBB}$ conceived, and coordinated the study, and participated in writing the manuscript. All authors read and approved the final manuscript.

\section{Additional material}

\section{Additional file 1}

Genes with lower expression in wild-type versus $\Delta \mathrm{ccpA}$ mutant. The table represents genes showing a lower gene expression in the wild-type than the $\triangle \mathrm{ccpA}$ mutant (wt/mutant ratio $\leq 0.5$ ). Cells were grown in $L B$, without glucose addition.

Click here for file

[http://www.biomedcentral.com/content/supplementary/14712180-9-95-S1.doc]

\section{Additional file 2}

Genes with higher expression in wild-type versus $\Delta \mathrm{ccpA}$ mutant. The table represents genes showing a higher gene expression in the wild-type than the $\triangle \mathrm{ccpA}$ mutant (wt/mutant ratio $\geq 2.0$ ). Cells were grown in $L B$, without glucose addition.

Click here for file

[http://www.biomedcentral.com/content/supplementary/14712180-9-95-S2.doc]

\section{Additional file 3}

CcpA-dependent down-regulation by glucose. The table shows genes found to be subject to down-regulation by glucose in a CcpA-dependent manner (with/without glucose ratio of 0.5 or lower in wild-type, with/ without glucose ratio of approximately 1, but below 2 in the mutant). Click here for file

[http://www.biomedcentral.com/content/supplementary/14712180-9-95-S3.doc]

\section{Additional file 4}

CcpA-dependent up-regulation by glucose. The table shows genes found to be subject to up-regulation by glucose in a CcpA-dependent manner (with/without glucose ratio of 2 or higher in wild-type, with/without glucose ratio of approximately 1, but below 2 in the mutant).

Click here for file

[http://www.biomedcentral.com/content/supplementary/14712180-9-95-S4.doc]

\section{Additional file 5}

Primers used for the construction of DIG-labelled DNA probes. Click here for file

[http://www.biomedcentral.com/content/supplementary/14712180-9-95-S5.doc]

\section{Acknowledgements}

This study was supported by the Swiss National Science Foundation grants 3 I0000-I I 7707 (to BBB), 3 I00A0-I I 2370/I (to JS), and 3 I00A0- I I6075/ I (to PF) and the Deutsche Forschungsgemeinschaft (grant Bi I350/I-I to $\mathrm{MB})$.

\section{References}

I. Fujita Y: Carbon catabolite control of the metabolic network in Bacillus subtilis. Bioscience, Biotechnology, and Biochemistry 2009, 73(2):245-259.

2. Sonenshein AL: Control of key metabolic intersections in Bacillus subtilis. Nat Rev Microbiol 2007, 5( I 2):917-927.

3. Seidel G, Diel M, Fuchsbauer N, Hillen W: Quantitative interdependence of coeffectors, CcpA and cre in carbon catabolite regulation of Bacillus subtilis. FEBS / 2005, 272(I 0):2566-2577.

4. Singh K, Schmalisch M, Stülke J, Görke B: Carbon catabolite repression in Bacillus subtilis: quantitative analysis of repression exerted by different carbon sources. J Bacteriol 2008, 190(2I):7275-7284.

5. Lulko AT, Buist G, Kok J, Kuipers OP: Transcriptome analysis of temporal regulation of carbon metabolism by CcpA in Bacillus subtilis reveals additional target genes. I Mol Microbiol Biotechnol 2007, I 2(I-2):82-95.

6. Miwa Y, Fujita Y: Involvement of two distinct cataboliteresponsive elements in catabolite repression of the Bacillus subtilis myo-inositol (iol) operon. J Bacteriol 200I, I 83(20):5877-5884.

7. Miwa Y, Nakata A, Ogiwara A, Yamamoto M, Fujita Y: Evaluation and characterization of catabolite-responsive elements (cre) of Bacillus subtilis. Nucleic Acids Res 2000, 28(5): I206-I2I0.

8. Stülke J, Hillen W: Regulation of carbon catabolism in Bacillus subtilis. Annu Rev Microbiol 2000, 54(I):849-880.

9. Deutscher J: The mechanisms of carbon catabolite repression in bacteria. Curr Opin Microbiol 2008, I I (2):87-93.

10. Deutscher J, Francke C, Postma PW: How phosphotransferase system-related protein phosphorylation regulates carbohydrate metabolism in bacteria. Microbiol Mol Biol Rev 2006, 70(4):939-1031.

II. Voort M van der, Kuipers O, Buist G, de Vos W, Abee T: Assessment of CcpA-mediated catabolite control of gene expression in Bacillus cereus ATCC 14579. BMC Microbiology 2008, 8(I):62. 
12. Jankovic I, Egeter O, Brückner R: Analysis of catabolite control protein A-dependent repression in Staphylococcus xylosus by a genomic reporter gene system. I Bacteriol 2001, I 83(2):580-586.

13. Zomer AL, Buist G, Larsen R, Kok J, Kuipers OP: Time-resolved determination of the CCPA regulon of Lactococcus lactis subsp. cremoris MG I363. J Bacteriol 2007, I 89(4): |366-| 38|.

14. lyer R, Baliga NS, Camilli A: Catabolite control protein A (CcpA) contributes to virulence and regulation of sugar metabolism in Streptococcus pneumoniae. I Bacteriol 2005 I 87(24):8340-8349.

15. Abranches ], Nascimento MM, Zeng L, Browngardt CM, Wen ZT, Rivera MF, Burne RA: CcpA regulates central metabolism and virulence gene expression in Streptococcus mutans. I Bacteriol 2008, I 90(7):2340-2349.

16. Behari J, Youngman P: A homolog of CcpA mediates catabolite control in Listeria monocytogenes but not carbon source regulation of virulence genes. J Bacteriol 1998, I80(23):6316-6324.

17. Almengor AC, Kinkel TL, Day SJ, Mclver KS: The catabolite control protein CcpA binds to $P$ mga and influences expression of the virulence regulator Mga in the group A Streptococcus. J Bacteriol 2007, 189(23):8405-8416.

18. Shelburne SA III, Keith D, Horstmann N Sumby P, Davenport MT, Graviss EA, Brennan RG, Musser JM: A direct link between carbohydrate utilization and virulence in the major human pathogen group A Streptococcus. Proc Natl Acad Sci USA 2008, 105(5): $1698-1703$.

19. Wen ZT, Burne RA: Functional genomics approach to identifying genes required for biofilm development by Streptococcus mutans. Appl Environ Microbiol 2002, 68(3): I I96-I 203.

20. Bizzini A, Entenza JM, Moreillon P: Loss of penicillin tolerance by inactivating the carbon catabolite repression determinant CcpA in Streptococcus gordonii. J Antimicrob Chemother 2007, 59(4):607-615.

21. De Lencastre H, Wu SW, Pinho MG, Ludovice AM, Filipe S, Gardete S, Sobral R, Gill S, Chung M, Tomasz A: Antibiotic resistance as a stress response: complete sequencing of a large number of chromosomal loci in Staphylococcus aureus strain COL that impact on the expression of resistance to methicillin. Microb Drug Resist 1999, 5(3): 163-175.

22. Seidl K, Bischoff M, Berger-Bächi B: CcpA mediates the catabolite repression of tst in Staphylococcus aureus. Infect Immun 2008, 76( I I):5093-5099.

23. Seidl K, Goerke C, Wolz C, Mack D, Berger-Bächi B, Bischoff M: The Staphylococcus aureus CcpA affects biofilm formation. Infect Immun 2008, 76(5):2044-2050.

24. Seidl K, Stucki M, Rüegg M, Goerke C, Wolz C, Harris L, Berger-Bächi $B$, Bischoff M: Staphylococcus aureus CcpA affects virulence determinant production and antibiotic resistance. Antimicrob Agents Chemother 2006, 50(4): I I83-I I 94.

25. Sezonov G, Joseleau-Petit D, D'Ari R: Escherichia coli physiology in Luria-Bertani broth. J Bacteriol 2007, 189:8746-8749.

26. Database of the Genomes Annotated at Nite (DOGAN) [http://www.bio.nite.go.jp/dogan/MicroTop?GENOME ID=n315]

27. Kanehisa M: A database for post-genome analysis. Trends Genet 1997, 13(9):375-376.

28. Oskouian B, Stewart GC: Repression and catabolite repression of the lactose operon of Staphylococcus aureus. J Bacteriol 1990 I 72(7):3804-38|2.

29. Oskouian B, Stewart G: Cloning and characterization of the repressor gene of the Staphylococcus aureus lactose operon J Bacteriol 1987, 169( I 2):5459-5465.

30. Blumenthal HJ: Glucose catabolism in Staphylococci. In Staphylococci Edited by: Cohen JO. New York: Wiley-Intersience; 1972:111-135

31. Scovill W, Schreier H, Bayles K: Identification and characterization of the pckA gene from Staphylococcus aureus. I Bacteriol 1996, I 78(I I ):3362-3364.

32. Blencke H-M, Homuth G, Ludwig H, Mader U, Hecker M, Stülke J: Transcriptional profiling of gene expression in response to glucose in Bacillus subtilis: regulation of the central metabolic pathways. Metab Eng 2003, 5(2): I33-149.

33. Kohler C, Wolff S, Albrecht D, Fuchs S, Becher D, Büttner K, Engelmann S, Hecker M: Proteome analyses of Staphylococcus aureus in growing and non-growing cells: a physiological approach. Int J Med Microbiol 2005, 295(8):547-565.
34. Shivers RP, Dineen SS, Sonenshein AL: Positive regulation of Bacillus subtilis ackA by CodY and CcpA: establishing a potential hierarchy in carbon flow. Mol Microbiol 2006, 62(3):8I I-822.

35. Bischoff M, Dunman P, Kormanec J, Macapagal D, Murphy E, Mounts W, Berger-Bächi B, Projan S: Microarray-based analysis of the Staphylococcus aureus sigmaB regulon. I Bacteriol 2004, I 86( I 3):4085-4099.

36. Graham J, Wilkinson B: Staphylococcus aureus osmoregulation: roles for choline, glycine betaine, proline, and taurine. J Bacteriol I992, I 74(8):27| I-27I6

37. Hübscher J, Jansen A, Kotte O, Schafer J, Majcherczyk P, Harris L, Bierbaum G, Heinemann M, Berger-Bächi B: Living with an imperfect cell wall: compensation of femAB inactivation in Staphylococcus aureus. BMC Genomics 2007, 8(I):307.

38. Mobley HL, Hausinger RP: Microbial ureases: significance, regulation, and molecular characterization. Microbiol Rev 1989, 53(I):85-108.

39. Biswas R, Voggu L, Simon U, Hentschel P, Thumm G, Götz F: Activity of the major staphylococcal autolysin Atl. FEMS Microbiol Lett 2006, 259(2):260-268.

40. Koehl J, Muthaiyan A, Jayaswal R, Ehlert K, Labischinski H, Wilkinson $B$ : Cell wall composition and decreased autolytic activity and lysostaphin susceptibility of glycopeptide-intermediate Staphylococcus aureus. Antimicrob Agents Chemother 2004, 48(10):3749-3757.

4I. Belcheva A, Golemi-Kotra D: A close-up view of the VraSR twocomponent system: a mediator of Staphylococcus aureus response to cell wall damage. J Biol Chem 2008, 283(18): 12354-|2364

42. McCallum N, Spehar G, Bischoff M, Berger-Bächi B: Strain dependence of the cell wall-damage induced stimulon in Staphylococcus aureus. Biochim Biophys Acta 2006, I760(10): |475-8I.

43. Senn MM, Bischoff $M$, von Eiff $C$, Berger-Bächi $B$ : SigmaB activity in a Staphylococcus aureus hemB mutant. J Bacteriol 2005, 187(2I):7397-7406.

44. Luong T, Dunman P, Murphy E, Projan S, Lee C: Transcription profiling of the mgrA regulon in Staphylococcus aureus. J Bacterio 2006, I88(5): 1899-1910.

45. Grundmeier M, Hussain M, Becker P, Heilmann C, Peters G, Sinha B Truncation of fibronectin-binding proteins in Staphylococcus aureus strain Newman leads to deficient adherence and host cell invasion due to loss of the cell wall anchor function. Infect Immun 2004, 72(I 2):7|55-7|63.

46. Sinha $B$, Herrmann $M$ : Mechanism and consequences of invasion of endothelial cells by Staphylococcus aureus. Thromb Haemost 2005, 94:266-277.

47. Hauck C, Ohlsen K: Sticky connections: extracellular matrix protein recognition and integrin-mediated cellular invasion by Staphylococcus aureus. Curr Opin Microbiol 2006, 9(I):5-II.

48. Rice K, Mann E, Endres J, Weiss E, Cassat J, Smeltzer M, Bayles K: The cidA murein hydrolase regulator contributes to DNA release and biofilm development in Staphylococcus aureus. Proc Nat Acad Sci USA 2007, 104:8 I I3-8I I8.

49. Tobisch S, Zuhlke D, Bernhardt J, Stülke J, Hecker M: Role of CcpA in regulation of the central pathways of carbon catabolism in Bacillus subtilis. J Bacteriol 1999, I8I(22):6996-7004.

50. Moreno MS, Schneider BL, Maile RR, Weyler W, Saier MH: Catabolite repression mediated by the CcpA protein in Bacillus subtilis: novel modes of regulation revealed by whole-genome analyses. Mol Microbiol 200I, 39(5): I366-138I

5I. Grundy FJ, Wateres DA, Allen HG, Henkin TM: Regulation of the Bacillus subtilis acetate kinase gene by CcpA. I Bacteriol 1993, 175:7348-7355.

52. Renna MC, Najimudin N, Winik LR, Zahler SA: Regulation of the Bacillus subtilis alsS, alsD, and alsR genes involved in postexponential-phase production of acetoin. J Bacteriol 1993, 175:3863-3875.

53. Grundy FJ, Turinsky AJ, Henkin TM: Catabolite regulation of Bacillus subtilis acetate and acetoin utilization genes by CcpA. I Bacteriol I 994, I 76( I 5):4527-4533.

54. Ludwig H, Meinken C, Matin A, Stülke J: Insufficient expression of the ilv-leu operon encoding enzymes of branched-chain amino acid biosynthesis limits gowth of a Bacillus subtilis ccpA mutant. J Bacteriol 2002, I 84(18):5 I74-5178.

55. Shivers RP, Sonenshein AL: Bacillus subtilis ilvB operon: an intersection of global regulons. Mol Microbiol 2005, 56(6): I549-I559. 
56. Tojo S, Satomura T, Morisaki K, Deutscher J, Hirooka K, Fujita Y: Elaborate transcription regulation of the Bacillus subtilis ilvleu operon involved in the biosynthesis of branched-chain amino acids through global regulators of CcpA, CodY and TnrA. Mol Microbiol 2005, 56(6): $1560-1573$.

57. Duthie E, Lorenz LL: Staphylococcal coagulase; mode of action and antigenicity. J Gen Microbiol 1952, 6(I-2):95-107.

58. Renzoni A, Barras C, Francois $P$, Charbonnier Y, Huggler E, Garzoni C, Kelley WL, Majcherczyk P, Schrenzel J, Lew DP, et al.: Transcriptomic and functional analysis of an autolysis-deficient, teicoplanin-resistant derivative of methicillin-resistant Staphylococcus aureus. Antimicrob Agents Chemother 2006, 50(9):3048-306I.

59. Scherl A, Francois $P$, Charbonnier $Y$, Deshusses J, Koessler T, Huyghe A, Bento M, Stahl-Zeng J, Fischer A, Masselot A, et al:: Exploring glycopeptide-resistance in Staphylococcus aureus: a combined proteomics and transcriptomics approach for the identification of resistance-related markers. BMC Genomics 2006, 7(I):296.

60. Charbonnier $Y$, Gettler B, Francois P, Bento M, Renzoni A, Vaudaux $P$, Schlegel $W$, Schrenzel J: A generic approach for the design of whole-genome oligoarrays, validated for genomotyping, deletion mapping and gene expression analysis on Staphylococcus aureus. BMC Genomics 2005, 6(I):95.

6I. Kuroda M, Ohta T, Uchiyama I, Baba T, Yuzawa H, Kobayashi I, Cui L, Oguchi A, Aoki K-I, Nagai Y, et al.: Whole genome sequencing of meticillin-resistant Staphylococcus aureus. Lancet 200I, 357(9264): I225-1240.

62. Baba T, Takeuchi F, Kuroda M, Yuzawa H, Aoki K-i, Oguchi A, Nagai $Y$, Iwama N, Asano K, Naimi $T$, et al:: Genome and virulence determinants of high virulence community-acquired MRSA Lancet 2002, 359(9320): 1819-1827.

63. Gill SR, Fouts DE, Archer GL, Mongodin EF, DeBoy RT, Ravel J, Paulsen IT, Kolonay JF, Brinkac L, Beanan M, et al:: Insights on evolution of virulence and resistance from the complete genome analysis of an early methicillin-resistant Staphylococcus aureus strain and a biofilm-producing methicillin-resistant Staphylococcus epidermidis strain. I Bacteriol 2005, I 87(7):2426-2438.

64. Koessler $T$, Francois $P$, Charbonnier $Y$, Huyghe $A$, Bento $M$, Dharan S, Renzi G, Lew D, Harbarth S, Pittet D, et al: Use of oligoarrays for characterization of community-onset methicillin-resistant Staphylococcus aureus. J Clin Microbiol 2006, 44(3): I 040- 1048

65. Churchill GA: Using ANOVA to analyze microarray data. Biotechniques 2004, 37(2): 173-175. 177

66. Dalphin ME, Brown CM, Stockwell PA, Tate WP: The translational signal database, TransTerm, is now a relational database. Nucleic Acids Res 1998, 26(I):335-337.

67. McCallum N, Karauzum H, Getzmann R, Bischoff M, Majcherczyk P, Berger-Bächi $B$, Landmann $R$ : In vivo survival of teicoplaninresistant Staphylococcus aureus and fitness cost of teicoplanin resistance. Antimicrob Agents Chemother 2006, 50(7):2352-2360.

68. Martin-Verstraete I, Stülke J, Klier A, Rapoport G: Two different mechanisms mediate catabolite repression of the Bacillus subtilis levanase operon. J Bacteriol 1995, 177(23):6919-6927.

69. Weickert M, Chambliss G: Site-directed mutagenesis of a catabolite repression operator sequence in Bacillus subtilis. Proc Natl Acad Sci USA 1990, 87( 16):6238-6242.

70. Zalieckas JM, Wray LV Jr, Fisher SH: Expression of the Bacillus subtilis acs $A$ gene: position and sequence context affect cremediated carbon catabolite repression. J Bacteriol 1998 [ 80(24):6649-6654.

7I. Büttner K, Bernhardt J, Scharf C, Schmid R, Mäder U, Eymann C, Antelmann $\mathrm{H}$, Völker A, Völker U, Hecker M: A comprehensive two-dimensional map of cytosolic proteins of Bacillus subtilis. Electrophoresis 200I, 22:2908-2935.

72. Candiano G, Bruschi M, Musante L Santucci L Ghiggeri G Carnemolla B, Orecchia P, Zardi L, Righetti P: Blue silver: a very sensitive colloidal Coomassie G-250 staining for proteome analysis. Electrophoresis 2004, 25(9):| 327-I333.

73. Eymann C, Dreisbach A, Albrecht D, Bernhardt J, becher D, Gentner S, Tam LT, Büttner K, Buurmann G, Scharf C, et al.: A comprehensive proteome map of growing Bacillus subtilis cells. Proteomics 2004, 4(2849-2876):
74. Christensen WB: Urea decomposition as a means of differentiating Proteus and Paracolon cultures from each other and from Salmonella and Shigella types. J Bacteriol 1946, 52:46I-466.
Publish with BioMed Central and every scientist can read your work free of charge

"BioMed Central will be the most significant development for disseminating the results of biomedical research in our lifetime. "

Sir Paul Nurse, Cancer Research UK

Your research papers will be:

- available free of charge to the entire biomedical community

- peer reviewed and published immediately upon acceptance

- cited in PubMed and archived on PubMed Central

- yours - you keep the copyright
BioMedcentral 